\title{
Effect of Aerobic Training and Pistacia atlantica Extract Consumption on Plasma Levels of Lipocalin-2 and Insulin Resistance Index in Streptozotocin-Induced Diabetic Rats
}

\author{
Hosseini M.* MSc, Shemshaki A. ${ }^{1}$ PhD, Saghebjoo M. ${ }^{2}$ PhD, Gharari Arefi R. ${ }^{2}$ MSc \\ *Physical Education Department, Physical Education \& Sport Sciences Faculty, University of Esfahan, Esfahan, \\ Iran \\ 1Physical Education Department, Physical Education \& Sport Sciences Faculty, Al-Zahra University, Tehran, \\ Iran \\ 2Physical Education Department, Physical Education \& Sport Sciences Faculty, University of Birjand, Birjand, \\ Iran
}

\begin{abstract}
Aims: Herbal medicines and their derivatives were considered for treatment of diabetes and its side effects, for a long time. On the other hand, aerobic training considered as an essential treatment of diabetes. The aim of this study was to determine the effect of aerobic training and Pistacia atlantica extract consuming on plasma levels of Lipocalin- 2 and insulin resistance index in Streptozotocin-induced diabetic male rats.

Materials \& Methods: In this experimental study, 40 male Wistar rats were divided into five groups; normal control, diabetic control, diabetic+training, diabetic+extract, and diabetic+training+extract. Diabetes was induced by Streptozotocin $(40 \mathrm{mg} / \mathrm{kg})$ intrapritoneal injection. 6 weeks of aerobic training on treadmill was the training program (5 sessions per week, each session 40 minutes at a speed of 20 meters per minute and the slope 5 degrees). At the end of each training session, extract groups received Pistacia atlantica extract $(25 \mathrm{mg} / \mathrm{kg})$, based on the body weight. After six weeks, plasma levels of insulin, glucose and Lipocalin-2 were determined. Statistical analysis was done in SPSS 19 software by one-away ANOVA and LSD as a post hoc test.

Findings: No significant difference was observed, among the 5 groups in the Lipocalin-2 level $(p=0.115)$, but the insulin resistance index (HOMA-IR), showed a significant difference among the 5 groups $(p=0.025)$. The mean amount of HOMA-IR index in diabetes+training $(\mathrm{p}=0.025)$ and diabetes+training+extract consuming $(p=0.017)$ groups in comparison to diabetic control group was significantly lower. There was no significant difference between HOMA-IR index in other diabetic groups ( $\mathrm{p}>0.05)$.

Conclusion: Aerobic training, alone and combined with Pistacia atlantica extract consumption, by reducing insulin resistance, improves the oxidation disturbance effects of diabetes.
\end{abstract}

\section{Keywords}

Exercise [www.ncbi.nlm.nih.gov/mesh/68015444];

Lcn2 Protein, Rat [www.ncbi.nlm.nih.gov/mesh/C097278];

Insulin Resistance [www.ncbi.nlm.nih.gov/mesh/68007333];

Diabetes Mellitus [www.ncbi.nlm.nih.gov/mesh/68003920];

Plants, Medicinal [www.ncbi.nlm.nih.gov/mesh/68010946]

\author{
*Corresponding Author \\ Tel: +985632416951 \\ Fax: +985632202032 \\ Address: Unit 3, No 24, Razavieh 11, Sajadshahr Street, South Khorasan, Birjand, Iran. Postal Code: 9716946178 \\ hoseyni_mahshid68@yahoo.com \\ Received: February 7, $2015 \quad$ Accepted: August 15, 2015 ePublished: December 15, 2015
}


كليدوازهها: تمرين هوازى، لييوكالين r، مقاومت به انسولين، ديابت، كياهان

دارويى

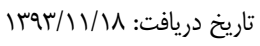

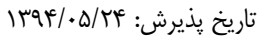

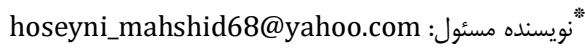

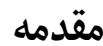

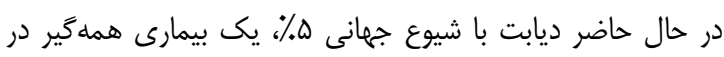

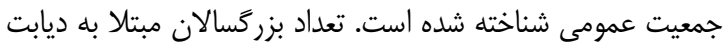

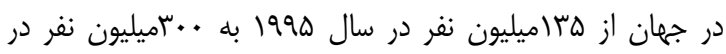

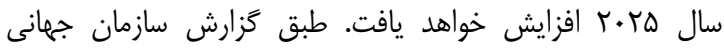

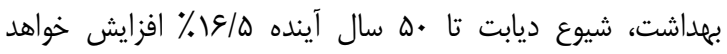

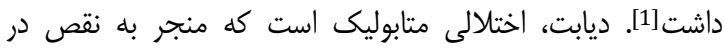

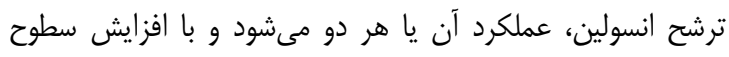

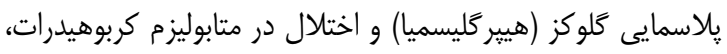

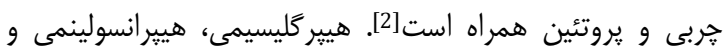
مقاومت به انسولين منجر به افزايش سطح استرس اكسيداتيو و در

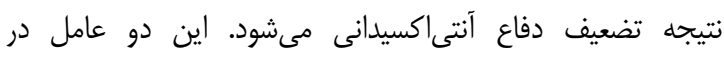

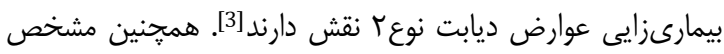

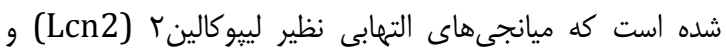

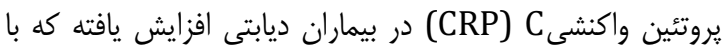

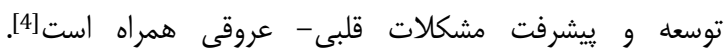

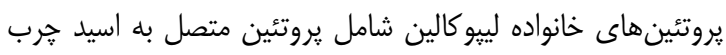

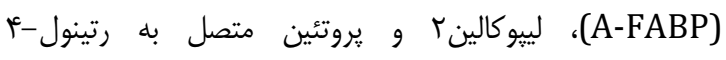

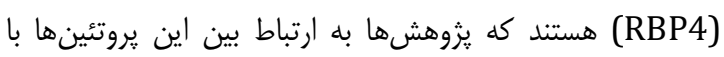

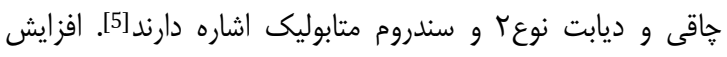
بيان Lcn2 تحت شرايط بسيارى مانند استرس اكسيداتيو، تنش

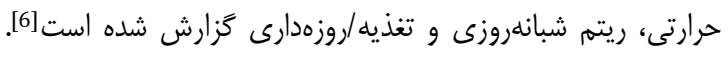

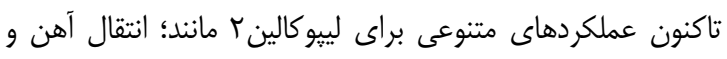

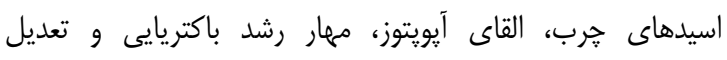

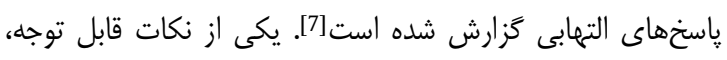

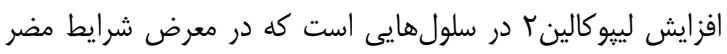

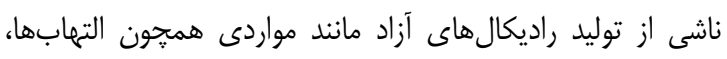

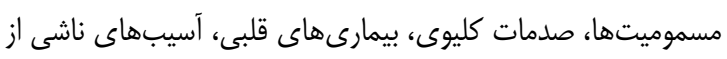

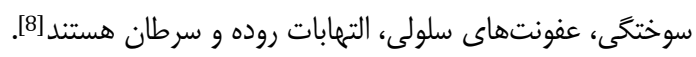

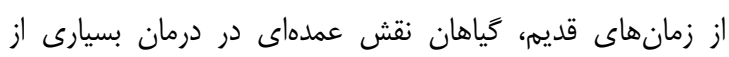

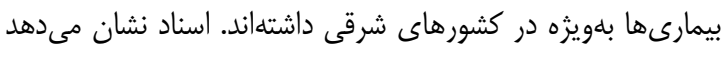

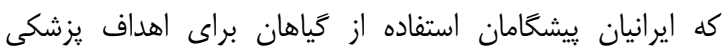

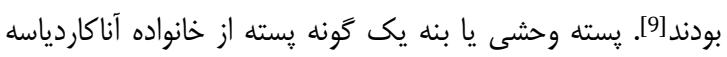

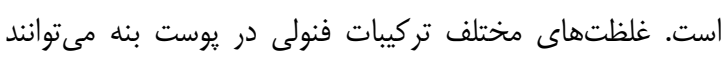

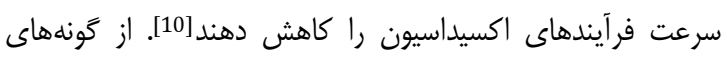

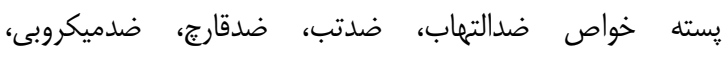

اثر تمرين هوازى و مصرف عصارن إنداره بيستاسيا

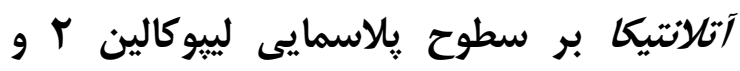

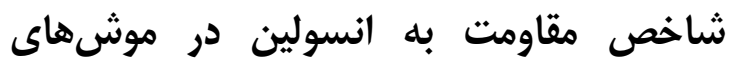
ديابتىشده با استريتوزوتوسين

MSc مهشيد حسينى

كروه تربيت بدنى، دانشكده تربيت بدنى و علوم ورزشى، دانشكاه اصفهان،

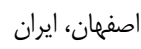

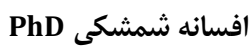

كروه تربيت بدنى، دانشكده تربيت بدنى و علوم ورزشى، دانشكاه الزهرا(س).

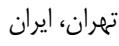

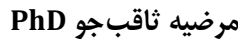

كروره تربيت بدنى، دانشكده تربيت بدنى و علوم ورزشى، دانشَاه بيرجند، بيرجند،

ايران

رضا قرارى عارفى MSc

كروهه تربيت بدنى، دانشكده تربيت بدنى و علوم ورزشى، دانشكاه بيرجند، بيرجند، ايران

جكيده

اهداف: كياهان دارويى و مشتقات آنها از ديرباز در درمان ديابت و ورئ

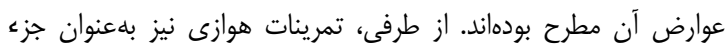

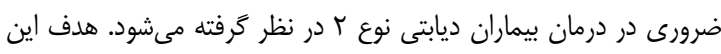

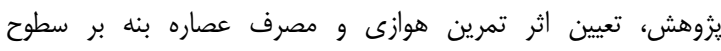

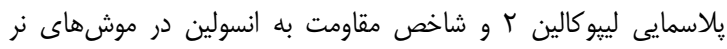

ديابتى شده با استر يتوزوتوسين بودا

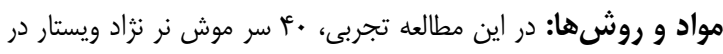

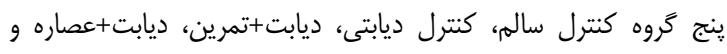

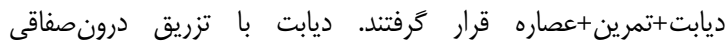

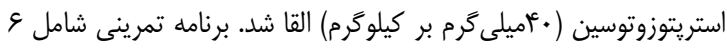

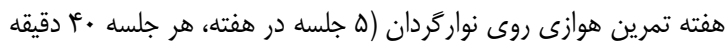

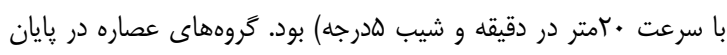

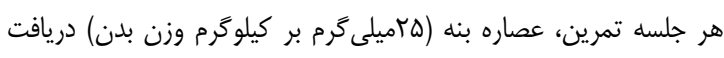

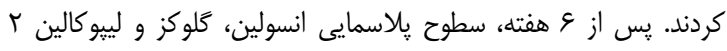

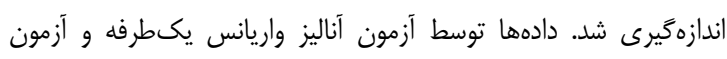

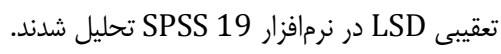

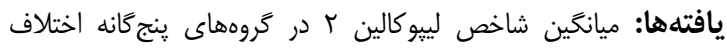

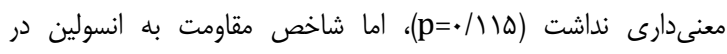

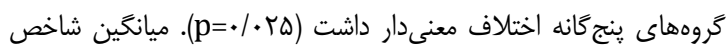

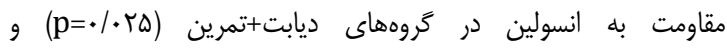

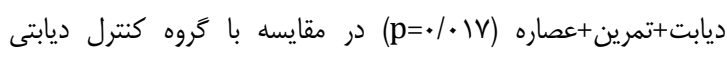

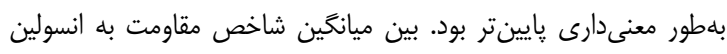

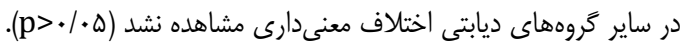

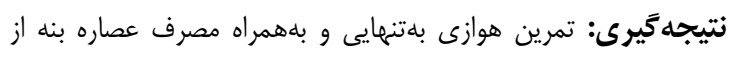

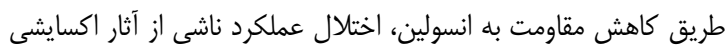

دوره rז، شماره ا، زمستان Iraf

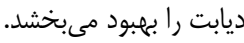
فصلنامه افق دانش 
اثر تمرين هوازى و مصرف عصاره يِيستاسيا آتلانتيكا بر سطوح يلاسمايى لييوكالين ؟ و شاخص مقاومت به انسولين ...

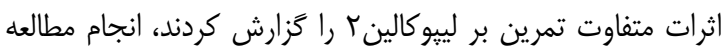
روى متغيرهاى مذكور در نمونهاى ديابتى ضرورى بلنظر مىرسد

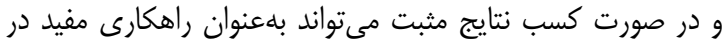

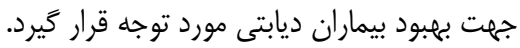
هدف از اجراى اين يزوهش، تعيين اثر تمرين هوازى و مصرف بورئه

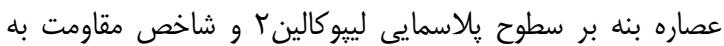
انسولين در موشهاى نر ديابتى شده با استريتوزوتوسين بود.

\section{مواد و روشها}

در اين مطالعه تجربى، ·+ سر موش صحرايى نر نثاد ويستار

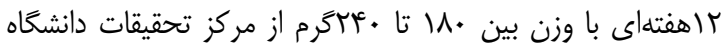

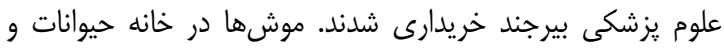

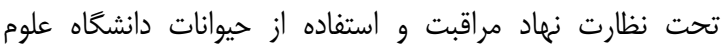

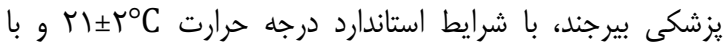

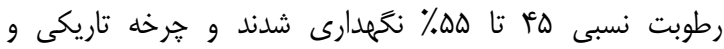

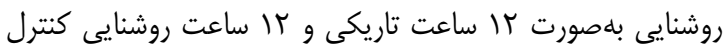

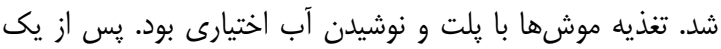
هفته سازگارى موشها با محيط آزمايشگاه، براى ايجاد ديابت از

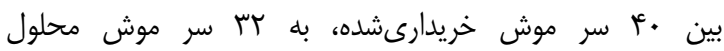

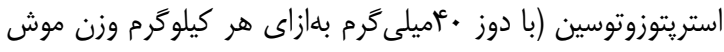

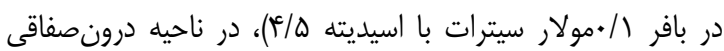
تزريق شد. قند خون موشها يس از ه روز با خونخيرى از نوى دئ دم

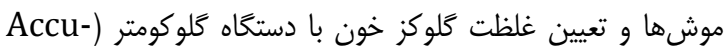
Chek دسىليتر بهعنوان معيار ديابتىشدن در نظر گرفته شد [19].

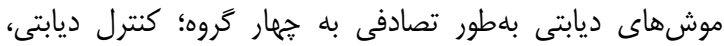
ديابت+تمرين، ديابت+تمرين +عصاره و ديابت+عصاره تقبس بهيم شدند و به اين ترتيب با 1 سر موشى كه بهطور تصادفى در ابتدا بهعنوان

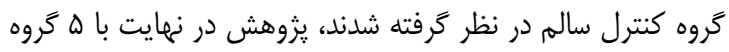

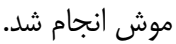

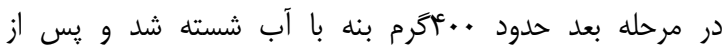

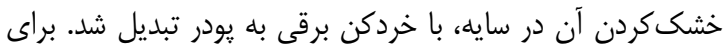

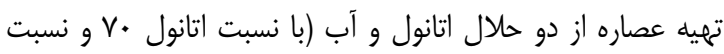

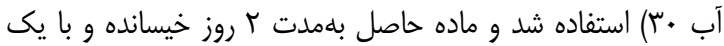

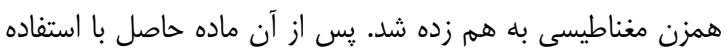

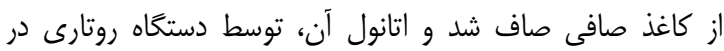
شرايط خلاء تبخير شد. مايع تغليظشده در يليتهاى شيشهاى در

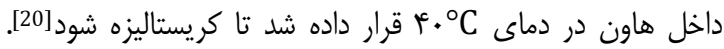
سرانجام عآكرم عصاره خشك بلهدست آمد كه نسبت عصاره حاصل داصل

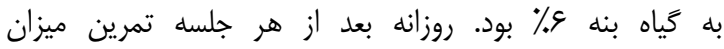
هاميلى

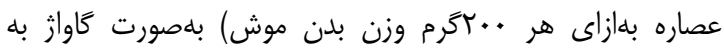

ضدويروسى، ضدآتروزنيك، هييو كليسميك، ضدسرطان و محافظ أر تمرين فعاليت كبدى گزارش شده است[11]. تحقيقاتى روى تركيبات شيميايى بنه صورت گرفته است و مشخص شده است كه عصاره اين گياه سرشار از آنتىاكسيدانهايى از جمله استرول و فيتواسترول (1)/9/9)

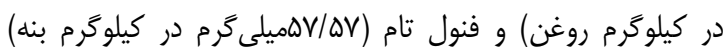
است. توكوفرول و فنولها مىتوانند بلهنوان يك آنتى اكسيدان

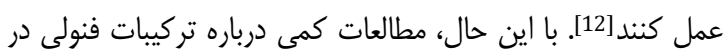
بنه، كه آنتىاكسيدان قوى و جاذب راديكالهاى آزاد است، وجود دارد[13]. بخشهاى خارجى يا صمغ اين گياه نيز در طب سبن سنى

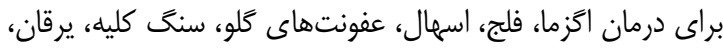

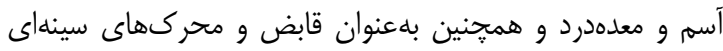
استفاده مىشود[11]. بنه حاوى هنهين همدين تركيب بيواكتيو و ارتقادهنده

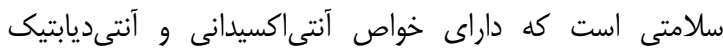
است] اخر جه از ديرباز گياهان دارويى و مشتقات آنها در درمان ديابت

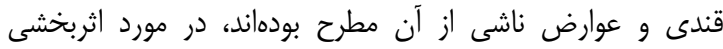

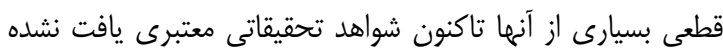

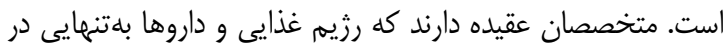
درمان و كنترل قند خون و متابوليزم جربىهاى خون بيماران ديابتى ندانى كافى نيستند، بلكه انجام فعاليتهاى بدنى و ورزشى وني نيز بايد به

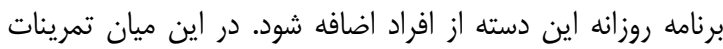

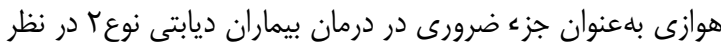

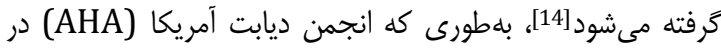

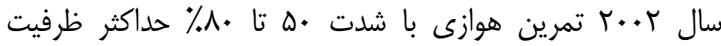

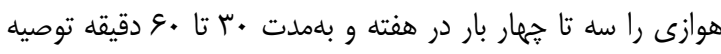

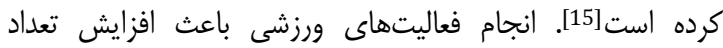

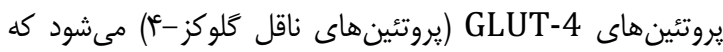
باعث كاهش كلوكز خون ناشتا و در نهايت كاهش مقاومت به به انسولين مىشود[16]. فعاليت ورزشى هوازى باعث باعث كاهش وزت وزن،

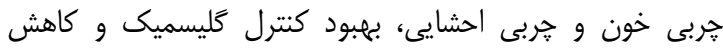

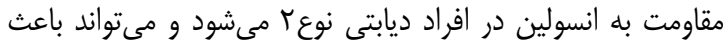

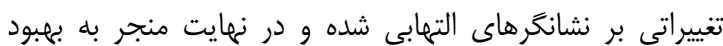
حساسيت به انسولين شود [15, 17, 18. بلنظر مىرسد تاكنون :ثروهشى كه بلهطور همزمان تاثير يك دوره

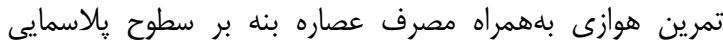

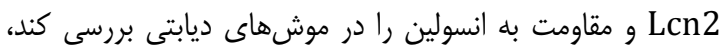
مشاهده نشده است. با توجه به كمبود اطلاعات مستقيم درباره

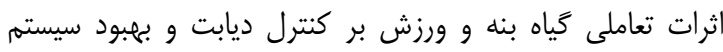

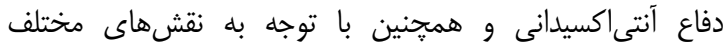

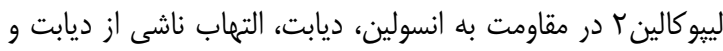

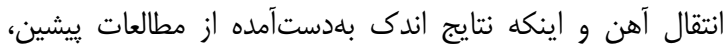




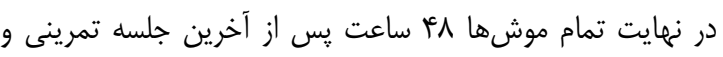

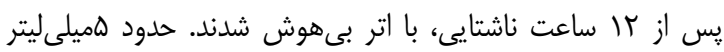

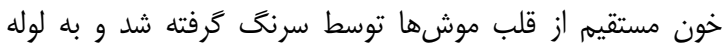

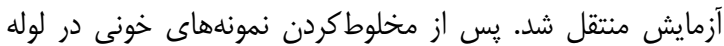

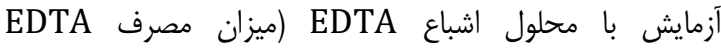

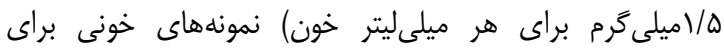

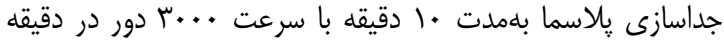

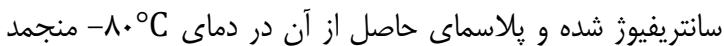

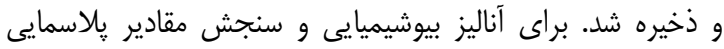

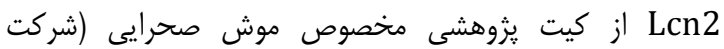
CUSABIOBIOTECH,Wuhan

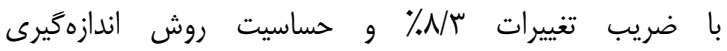

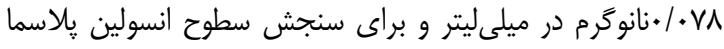

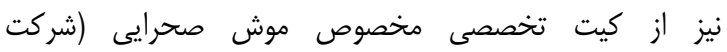
Mercodia, Uppsala

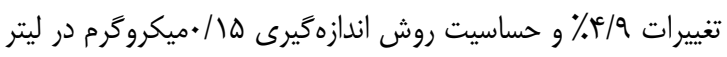

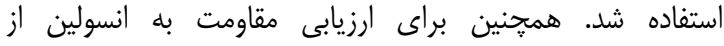

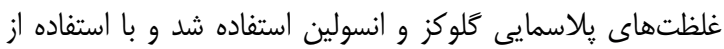
فرمول HOMA-IR محاسبه شد [3]:

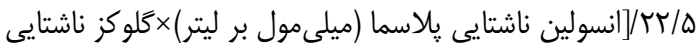

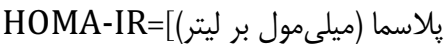

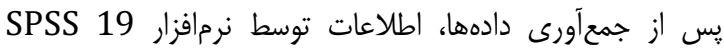

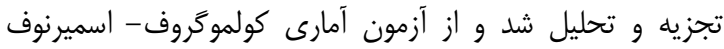

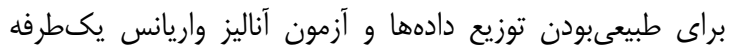

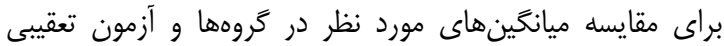
LSD براى مقايسه جفتى استفاده شد.

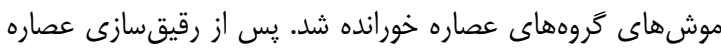
مذكور در سرم فيزيولوزى، حجم ماده كاوازشده، بهازاى هر موش

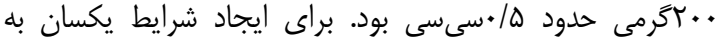

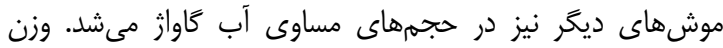

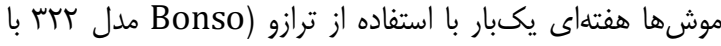

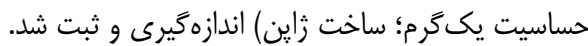
برنامه تمرينى شامل و هفته تمرين هوازى روى نوار كردان و تعداد

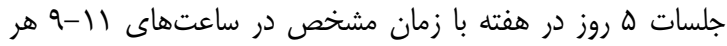

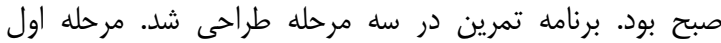

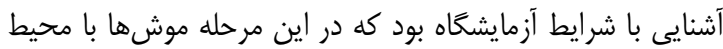
آزمايشگاه و دست كارى توسط انسان و كار روى نوار كردان آشنا

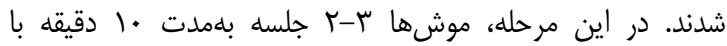
سرعت • (1-همتر در دقيقه و شيب صفر، روى نوار گردان راه رفتيند.

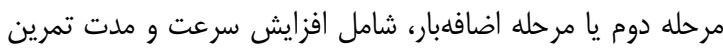

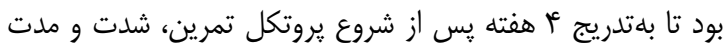

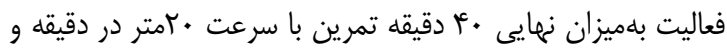

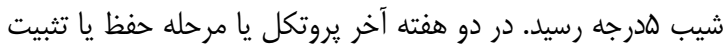

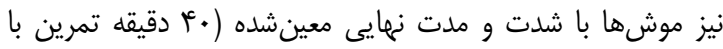

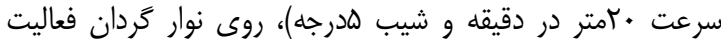

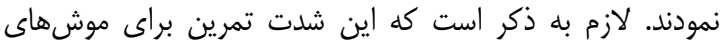

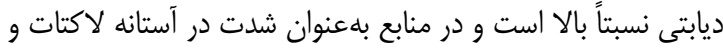

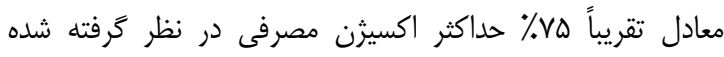

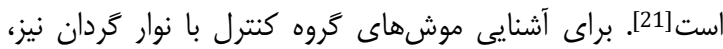

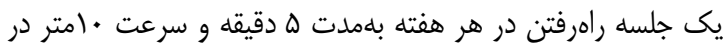

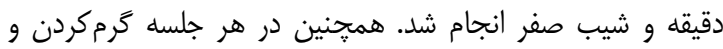

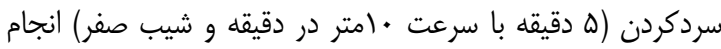

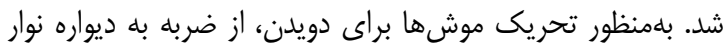
كردان همراه با شوك الكتريكى با ولتاز كم استفاده مى نشد.

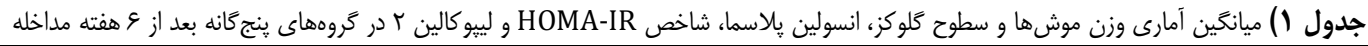

\begin{tabular}{|c|c|c|c|c|c|}
\hline ديابت+عصاره & ديابت+عصاره+تمرين & $\begin{array}{c}\text { تمرين ديابتى (عر) } \\
\text { (عرير }\end{array}$ & 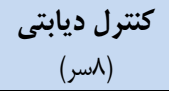 & كنتر ل سالم & متغير ها \\
\hline $\begin{array}{l}|R Q / \cdots \pm r| / \cdots \\
r \cdot V / \cdots \pm r t / \cdots\end{array}$ & $\begin{array}{l}r|1 / \cdots \pm| \varepsilon / \cdots \\
19 r / \cdots \pm r \cdot \cdots\end{array}$ & $\begin{array}{l}r \cdot \varepsilon / \Delta \cdot \pm \mid N / \cdot \varepsilon \\
199 / \Lambda r \pm \Delta \& / r \varepsilon\end{array}$ & 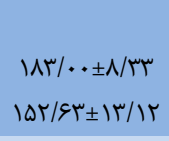 & $\begin{array}{l}r r / / r \pm 11 / \Delta q \\
r R / / r \Delta \pm 19 / \Delta \Lambda\end{array}$ & يسش آزمون (كرم) \\
\hline 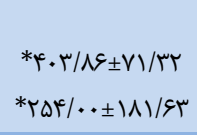 & 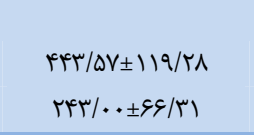 & $\begin{array}{l}r V D / r r \pm V R / Q . \\
r \cdot 1 / 9 q \pm 11 r / \wedge q\end{array}$ & $\begin{array}{l}r \varepsilon Y / \cdot \cdot \pm r V / \cdots \\
r V q / \cdot \cdot \pm \mid Q / \cdot 1\end{array}$ & $\begin{array}{l}N \varepsilon / \Delta \cdot \pm I r / \Delta F \\
V N / T \Delta \pm q / / q\end{array}$ & 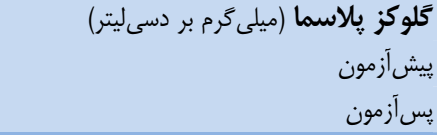 \\
\hline זו// & $\cdot / r \cdot \pm \cdot / \cdot \Delta$ & $\cdot / T \Lambda \pm \cdot / 1 Q$ & $. / 19 \pm \cdot / \cdot r$ & $\cdot|\Delta| \pm \cdot / T \cdot$ & 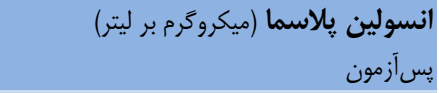 \\
\hline$* \Gamma / r \Delta \pm I / \Delta \Delta$ & $r / V q_{ \pm} \cdot / V \Delta$ & $r / q \cdot \pm 1 / \cdot q$ & $\uparrow / \Gamma \Delta \pm \cdot / \varepsilon \Delta$ & $r / \Delta \Delta \pm 1 / T C$ & مقآزمت به انسولين (شاخص HOMA-IR) \\
\hline$\Delta / V T \pm r / \cdot r$ & $\Delta / G Y \pm I / V G$ & G/ATII/r. & $\Gamma / \Delta \cdot \pm 1 / \varepsilon \Lambda$ & $r / q \Psi \pm 1 / 1 Q$ & 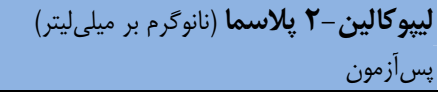 \\
\hline
\end{tabular}




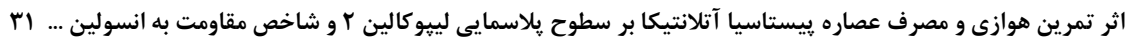

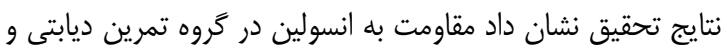

يافتهها

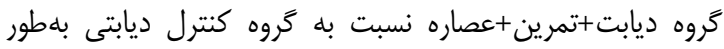

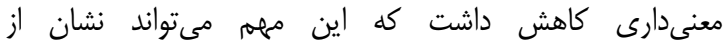
سازكارىهاى سطح سلولى ناشى از تمرين و عصاره باشد. يافتههاى

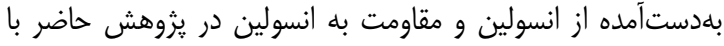
يافتههاى بلوم و همكاران همراستا بود. آنها اظهار داشتند كه فعاليت ورزشى كوتاهمدت با شدت متوسط نهتنها موجب كاهش مقاومت به به

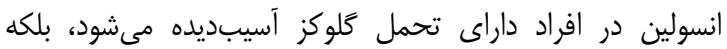
موجب بهبود عملكرد سلولهاى بتاى پانكراس نيز مى شود [28].

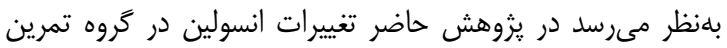

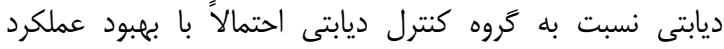

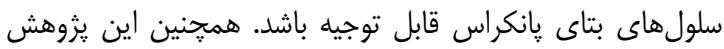
نشان داد كه 9 هفته تمرين هوازى همراه و بلدون مصرف عصدئ عصاره بنه سطوح Lcn2, را تغيير معنىدارى نمىدهد. در اين راستا

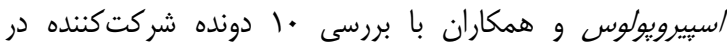

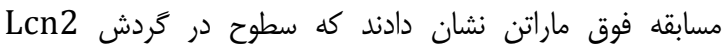

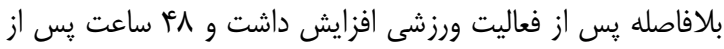

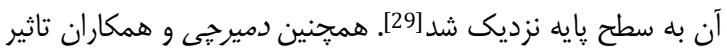
يك جلسه فعاليت ورزشى فزاينده روى نوار گردان را در افراد جاق بررسى كردند. نتايج آنما نشان داد كه سطوح شاخص التهابى يس از انجام يك نوبت فعاليت ورزشى فزاينده

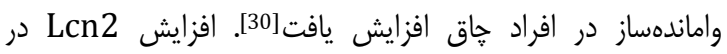

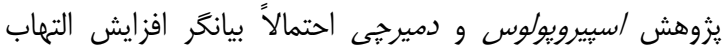

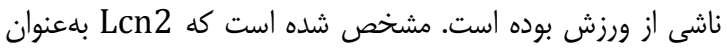

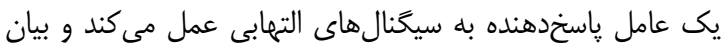

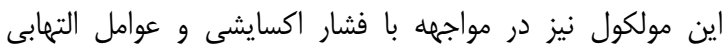

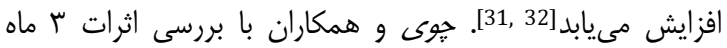
تمرين هوازى و قدرتى روى يروتئينهاى خانواده لييوكالين و و

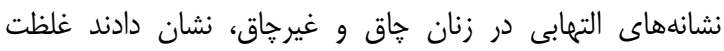

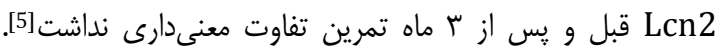

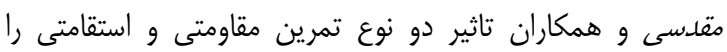
بلممدت 1 هفته بر سطح Lcn2 يلاسما مردان جوان سالم مورد مطالعه قرار دادند. نتايج آنها نشان داد ^ م هفته تمرين استقامتى و مقاومتى باعث كاهش معنىدار در سطح Lcn2 نسبت به گروها

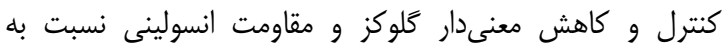

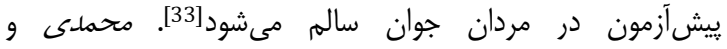
خواجهلندى تاثير 1 هفته تمرين هوازى را بر مردان سالم دارن داري اضافهوزن بررسى كردند كه نتايج آنها نشان داد 1 هفته تمرين لمرين هوازى باعث كاهش Lcn2 مىشود[34]. اين در حالى است كه در

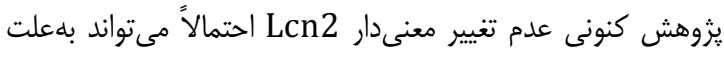
نوع آزمودنى ها و مدت تمرين عدم تعير معنير

فقط در شاخص HOMA-IR در كروههاى ینج كانه اختلاف

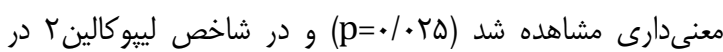

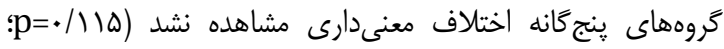

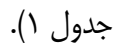

ميانگين شاخص HOMA-IR در گروه كنترل ديابتى در مقايسه با

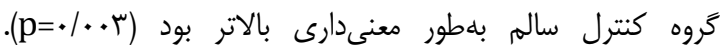

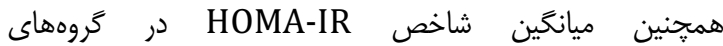

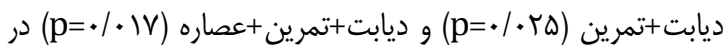

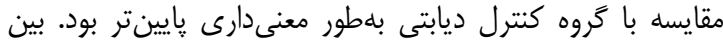

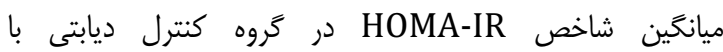

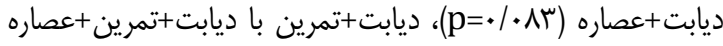

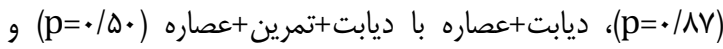

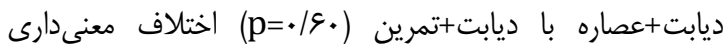

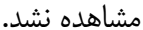

بحث

يافتهاى اين يزوهش كاهش سطح كلوكز پِاسمايى، بهبود

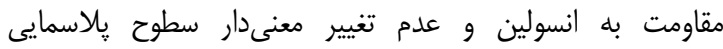

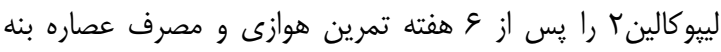
نشان داد. قنبرى نياكى و همكاران تاثير تمرين هوازى و عصاره بنه

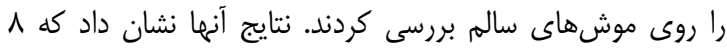
هفته تمرين هوازى و مصرف عصاره بنه تاثير معنى دارى بر كلوكز

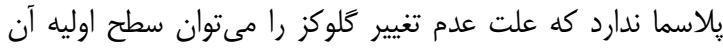

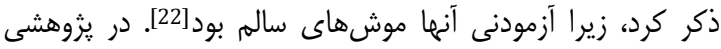

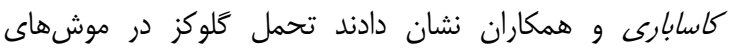

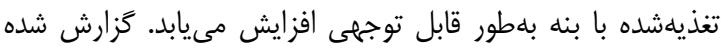

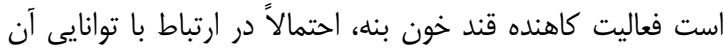

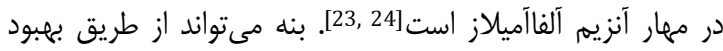

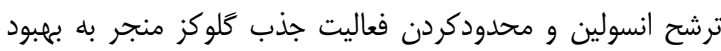

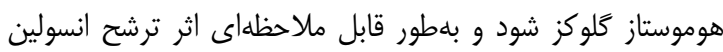

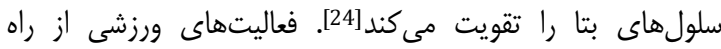

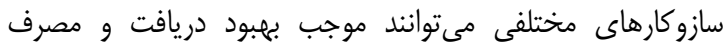

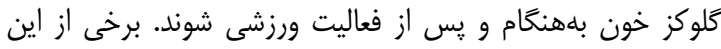
سازوكارها، افزايش جريان خون عضلانى، افزايش اتصال انسولين

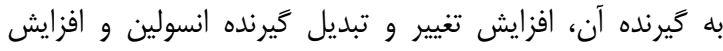

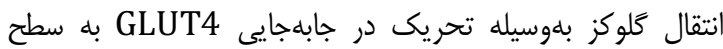
سلول عضلانى هستند [25, 26]. فعاليت ورزشى از راه راه كاهش تودها

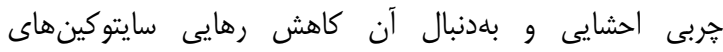
ييشالتهابى و ايجاد محيطى ضدالتهابى در كنترل بيمارىهاى مرتبط با التهاب، نظير ديابت تاثير بسز ايیى دارد[27]. 
2- Azizi Z, Mansoorpoor S, Sabzehvarifard A, Asaie S, Ranjbar Omrani Gh. Effect of Estradiol valerate on pancreatic beta cells resistance in diabetic female rats by streptozotocin. Iran South Med J. 2014;17(2):107-19. [Persian]

3- Haghighat N, Vafa M, Eghtesadi S, Heidari I, Hoseini AF. The effects of Tocotrienolsenriched canola oil on glycemic control and oxidative stress in patients with type 2 diabetes: A double blind randomized clinical trial. Razi J Med Sci. 2013;20(109):52-61. [Persian]

4- Wang Y, Lam KS, Kraegen EW, Sweeney G, Zhang J, Tso AW, et al. Lipocalin-2 is an inflammatory marker closely associated with obesity, insulin resistance, and hyperglycemia in humans. Clin Chem. 2007;53(1):34-41. 5- Choi K, Kim T, Yoo H, Lee K, Cho G, Hwang T, et al. Effect of exercise training on A-FABP, lipocalin-2 and RBP4 levels in obese women. Clin Endocrinol. 2009;70(4):569-74.

6- Scheer F, Chan J, Fargnoli J, Chamberland J, Arampatzi $\mathrm{K}$, Shea S, et al. Day/night variations of high-molecularweight adiponectin and lipocalin-2 in healthy men studied under fed and fasted conditions. Diabetologia. 2010;53(11):2401-5.

7- Cowland JB, Sørensen OE, Sehested M, Borregaard N. Neutrophil gelatinase-associated lipocalin is upregulated in human epithelial cells by IL-1 $\beta$, but not by TNF- $\alpha$. J Immunol. 2003;171(12):6630-9.

8- Bahmani P, Halabian R, Masrouri N, Rouhbakhsh M, Ebrahimi M, Nourani $M$, et al. Induction of heme oxygenase- 1 by lipocalin 2 mediated by NF-KB transcription factor. J Iran Anat Sci. 2009;1(27):33-44. [Persian]

9- Mohammadi Karizno F, Saghebjoo M, Foadoddini M, Sarir $\mathrm{H}$. The role of aerobic training and Pistacia atlantica extract on the levels of protein carbonyl, heat shock protein 70, and glycogen in the liver tissue of diabetic rats. J Birjand Univ Med Sci. 2014;21(1):35-47. [Persian] 10- Farzanegi P, Mousavi M, Ghanbari-Niaki A. Effect of Pistacia atlantica extract on glutathione peroxidase tissue levels and total oxidative capacity of liver and plasma lipid profile of rats. Zahedan J Res Med Sci. 2013;15(11):59-63. [Persian]

11- Peksel A, Arisan-Atac I, Yanardag R. Evaluation of antioxidant and antiacetylcholinesterase activities of the extracts of Pistacia atlantica Desf. Leaves. J Food Biochem. 2010;34(3):451-76.

12- Saber-Tehrani M, Givianrad MH, Aberoomand-Azar P, Waqif-Husain S, Jafari Mohammadi SA. Chemical composition of Iran's Pistacia atlantica cold-pressed oil. J Chem. 2013;(2013).

13- Hatamnia AA, Abbaspour N, Darvishzadeh R. Antioxidant activity and phenolic profile of different parts of Bene (Pistacia atlantica subsp. kurdica) fruits. Food Chem. 2014;145:306-11.

14- Rashidlamir A, Alizadeh A, Ebrahimiatri A, Dastani M. The effect of four-week period of aerobic exercise with cinnamon consumption on lipoprotein indicates and blood sugar in diabetic female patients (type 2). J Shahid Sadoughi Univ Med Sci. 2013;20(5):605-14. [Persian]

15- Colberg SR, Sigal RJ, Fernhall B, Regensteiner JG, Blissmer BJ, Rubin RR, et al. Exercise and type 2 diabetes. Diabetes Care. 2010;33(12):e147-67.

16- Richter EA, Hargreaves M. Exercise, GLUT4, and skeletal muscle glucose uptake. Physiol Rev. 2013;93(3):993-1017.

17- Bello AI, Owusu-Boakye E, Adegoke BO, Adjei DN.

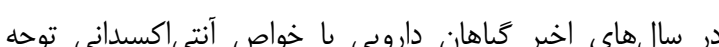
زيادى را به خود جلب كرده است و اعتقاد بر اين است كه اين

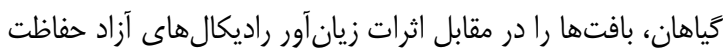

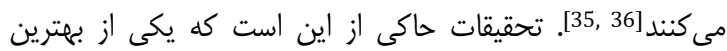

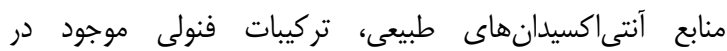

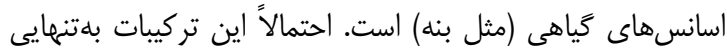

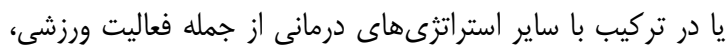

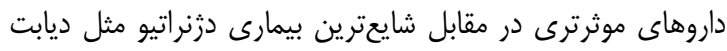

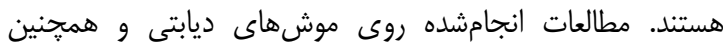

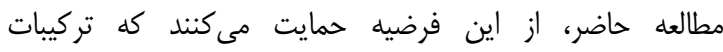

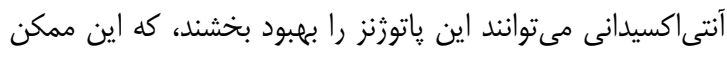
است ناشى از اثرات مستقيم اين تركيبات روى ترشح انتى انسولين، ييشخيرى از تخريب سلولهاى بتا يا حتى از طريق تنظيم ازدياد سلولهاى بتا باشد [36].

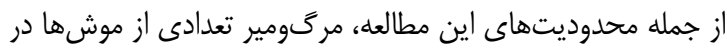

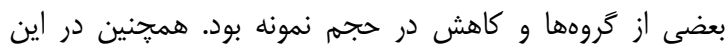

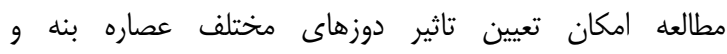

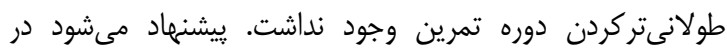

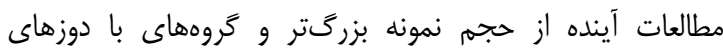
مختلف عصاره و شدتهاى مختلف تمرين هوازى در دورههاى تمرينى طولانى تر استفاده شود.

\section{نتيجه كَيرى}

تمرين هوازى بلتنهايى و بههمراه مصرف عصاره آنتىاكسيدانى بنه

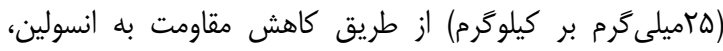

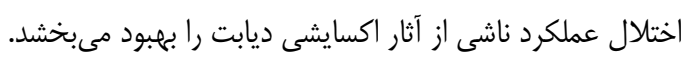

تشكر و قدردانى: نويسندكان مراتب تشكر و قدردانى خود را از

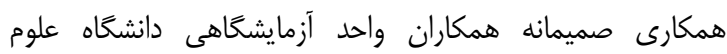

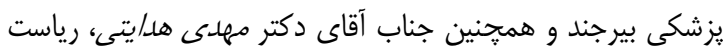

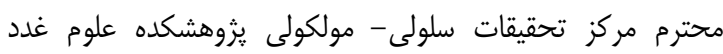

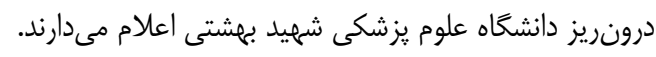

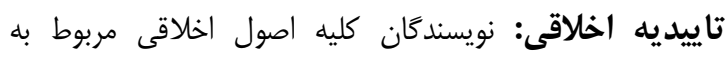

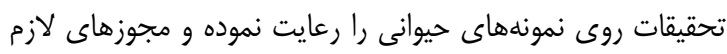
را از مراجع ذنى صلاح اخذ نمودند.

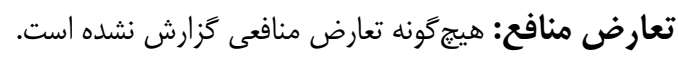
منابع مالى: مطالعه حاضر بدون حمايت مالى انجام شده است تعارض.

\section{منابع}

1- Zimmet PZ, Magliano DJ, Herman WH, Shaw JE. Diabetes: A 21st century challenge. Lancet Diabetes Endocrinol. 2014;2(1):56-64. 


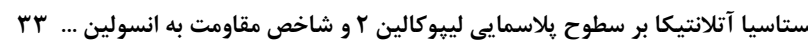

27- Gleeson M, Bishop NC, Stensel DJ, Lindley MR, Mastana SS, Nimmo MA. The anti-inflammatory effects of exercise: mechanisms and implications for the prevention and treatment of disease. Nat Rev Immunol. 2011;11(9):607-15.

28- Bloem CJ, Chang AM. Short-term exercise improves $\beta$-cell function and insulin resistance in older people with impaired glucose tolerance. J Clin Endocrinol Metab. 2008;93(2):387-92.

29- Spiropoulos A, Goussetis E, Margeli A, Premetis E, Skenderi K, Graphakos S, et al. Effect of inflammation induced by prolonged exercise on circulating erythroid progenitors and markers of erythropoiesis. Clin Chem Lab Med. 2010;48(2):199-203.

30- Damirchi A, Rahmani-Nia F, Mehrabani J. Lipocalin-2: Response to a progressive treadmill protocol in obese and normal-weight men. Asian J Sports Med. 2011;2(1):44.

31- Hemdahl AL, Gabrielsen A, Zhu C, Eriksson P, Hedin U, Kastrup J, et al. Expression of neutrophil gelatinaseassociated lipocalin in atherosclerosis and myocardial infarction. Arterioscler Thromb Vasc Biol. 2006;26(1):136-42.

32- Owen HC, Roberts SJ, Ahmed SF, Farquharson C. Dexamethasone-induced expression of the glucocorticoid response gene lipocalin 2 in chondrocytes. Am J Physiol Endocrinol Metab. 2008;294(6):1023-34.

33- Moghadasi M, Mohammadi Domieh M. Effects of resistance versus endurance training on plasma lipocalin-2 in young men. Asian J Sports Med. 2014 ;5(2):108-14.

34- Mohammadi A, Khajehlandi A. Hs-CRP and adipokin (Lcn2): Response to exercise training in obese men. Biomed Pharmacol J. 2014;7(1):17-22.

35- Bahadoran Z, Mirmiran P, Hosseinpanah F, Hedayati M, Hosseinpour-Niazi S, Azizi F. Broccoli sprouts reduce oxidative stress in type 2 diabetes: A randomized double-blind clinical trial. Eur J Clin Nutr. 2011;65(8):972-7.

36- Mahmudzadeh T, Saghebjoo M, Seghatol Eslami A, Hedayati M. Effect of aerobic training and Pistacia atlantica extract consumption on pancreatic $\beta$-cells function in streptozotocin-induced diabetic rats. Iran J Diabetes Metab. 2014;13(3):252-62. [Persian]
Effects of aerobic exercise on selected physiological parameters and quality of life in patients with type 2 diabetes mellitus. Int J Gen Med. 2011;4:723-7.

18- Yousefipoor P, Tadibi V, Behpoor N, Parnow A, Delbari M, Rashidi S. The effect of 8-week aerobic and concurrent (aerobic-resistance) exercise training on serum il- 6 levels and insulin resistance in type 2 diabetic patients. J Shahid Sadoughi Univ Med Sci. 2013;21(5):619-31.

19- Chis IC, Baltaru D, Maier M, Muresan A, Clichici S. Effects of quercetin and chronic (training) exercise on oxidative stress status in animals with Streptozotocininduced diabetes. Bull UASVM Vet Med. 2013;70(1):31-9. 20- Laghari AQ, Memon S, Nelofar A, Laghari AH. Extraction, identification and antioxidative properties of the flavonoid-rich fractions from leaves and flowers of Cassia angustifolia. Am J Anal Chem. 2011;2(8):871.

21- Kim HJ, Park JY, Oh SL, Kim YA, So B, Seong JK, et al. Effect of treadmill exercise on interleukin-15 expression and glucose tolerance in zucker diabetic fatty rats. Diabetes Metab J. 2013;37(5):358-64.

22- Ghanbari Niaki A, Fathi R, Shahandeh F, Yazdani M, Hajizadeh $A$. The effect of endurance training and Pistacia atlantica (bene) extraction on resting plasma visfatin and lipids levels in female rats. Daneshvar Med. 2011;18(94):53-62. [Persian]

23- Benhammou N, Bekkara FA, Panovska TK. Antioxidant and antimicrobial activities of the Pistacia lentiscus and Pistacia atlantica extracts. Afr J Pharm Pharmacol. 2008;2(2):022-8.

24- Kasabri V, AbuDahab R, Afifi FU, Naffa R, Majdalawi L. Modulation of pancreatic MIN6 insulin secretion and proliferation, and extrapancreatic glucose absorption with Achillea santolina, Eryngium creticum and Pistacia atlantica extracts: in vitro evaluation. J Exp Integr Med. 2012;2(3):245-54.

25- Zinman B, Ruderman N, Campaigne B, Devlin J, Schneider S. Physical activity/exercise and diabetes mellitus. Diabetes Care. 2003;26(Suppl1):S73-7.

26- Manetta J, Brun JF, Maimoun L, Callis A, Préfaut C, Mercier J. Effect of training on the GH/IGF-I axis during exercise in middle-aged men: relationship to glucose homeostasis. Am J Physiol Endocrinol Metab. 2002;283(5):E929-36. 